\title{
Validity of Health Assessment Questionnaire Disability Index (HAQDI) for Assessing Disease Activity in Iraqi Patients with Active Rheumatoid Arthritis
}

\author{
Ehab Mudher Mikhael ${ }^{1, *}$, Faiq Isho Gorial ${ }^{2}$ \\ ${ }^{1}$ Pharmacy College, University of Baghdad, Baghdad, Iraq \\ ${ }^{2}$ Medicine College, University of Baghdad, Baghdad, Iraq \\ *Corresponding author: ehab_pharma84@yahoo.com
}

Received June 9, 2013; Revised August 01,2013; Accepted August 08, 2013

\begin{abstract}
Objective: Rheumatoid arthritis is a common autoimmune disease associated with many complications like joint damage, disability and even death. It requires early and aggressive treatment with regular follow up to ensure safety and effectiveness of treatment for the patients. Disease activity score of 28 joints (DAS28) and simplified disease activity index (SDAI) are common tools that used to assess disease activity, whereas health assessment questionnaire disability index (HAQDI) is a patient reported tool for assessing patient functional ability. This study aimed to evaluate the effectiveness of HAQDI score for monitoring disease activity and response to therapy in Iraqi patients with active rheumatoid arthritis. Methods: A cross-sectional study was conducted in Baghdad Teaching Hospital, Rheumatology out patient Unit from August 2011 to May 2012. A total of 95 patients (21 males and 74 females) with active RA were involved in this study. Disease activity was measured by DAS28 and the SDAI whereas functional status of the patients was measured using HAQDI score. Results: There was a significant positive correlation of HAQDI score with clinical parameters like swelling joint count (SJC), tender joint count (TJC), visual analogue scale (VAS), physician global assessment (EGA) and morning stiffness. Additionally HAQDI was significantly correlated with disease activity scores DAS28 and SDAI. Furthermore it correlated with inflammatory markers ESR and CRP. HAQDI score was better correlated with clinical parameters in patients with high disease activity than those with moderate activity. Conclusion: HAQDI score is a valid and useful tool to monitor disease activity and response to treatment in Iraqi patients with highly active RA.
\end{abstract}

Keywords: rheumatoid arthritis, disease activity, disability, HAQDI

Cite This Article: Ehab Mudher Mikhael, and Faiq Isho Gorial, "Validity of Health Assessment Questionnaire Disability Index (HAQDI) for Assessing Disease Activity in Iraqi Patients with Active Rheumatoid Arthritis.” American Journal of Medical and Biological Research 1, no. 4 (2013): 91-94. doi: 10.12691/ajmbr-1$4-1$.

\section{Introduction}

Rheumatoid arthritis is a common chronic autoimmune disease with unknown etiology involving low grade systemic inflammation, characterized by articular and extra articular involvement, which can progress with time leading to joint damage, deformity, disability and even death $[1,2,3]$. The paradigm of RA treatment worldwide now is early, aggressive therapy with the goal being remission or the lowest disease activity state possible, maintained for the longest time period possible [4]. Although many effective drugs are available nowadays for treating RA patients [5], but many patients still suffer from a decreased response to disease modifying anti rheumatic drugs (DMARDs) after a period of time [6]; Furthermore some patients may develop disability despite using effective medications [7], this highlight the importance of continuous follow up for RA patients and assessing the disease activity regularly to ensure not only safety of the drug but also to ensure drug effectiveness and patient's response to it; However, this aspect is often neglected [8] may be because it is costly in terms of medical time, expertise and in the use of general health resources and can be in convenient to the patients especially those who are still in full or part time employment [9]. Many instruments have been validated that can be incorporated into routine clinical practice for monitoring RA disease activity and to aid in treatment decisions with the goal of optimizing clinical responses and reducing joint damage from RA [8]. At present, Disease Activity Score-28 joints (DAS28) and simplified disease activity score (SDAI) are two of the standard methods to measure the disease activity in patients of RA and to assess response to therapy $[10,11,12]$. Meanwhile health assessment questionnaire - disability index (HAQDI) assesses the extent of the patient's functional ability. It has been widely used for research purposes in both experimental and observational studies, as well as in clinical settings. The HAQ-DI is sensitive to change and is a good predictor of future disability and costs. It has been 
shown to be reliable and valid in different languages and contexts [13]. HAQDI was shown to be well correlated with DAS28 in detecting RA disease activity in Indian patients with early RA $[14,15,16,17,18]$.

This study aimed to evaluate the effectiveness of HAQDI score for monitoring disease activity and response to therapy in Iraqi patients with active rheumatoid arthritis.

\section{Patients and Methods}

\subsection{Study Design}

A cross-sectional study was conducted in Baghdad Teaching Hospital, Rheumatology out patient unit from August 2011 to May 2012. A total of 95 patients (21 males and 74 females) (Table 1) with active RA were involved in this study. Patients were diagnosed to have active RA by the rheumatologist. Ethical approval for research was obtained from the Ethics Committee of Baghdad University, College of Medicine, Department of Medicine. Patients with diseases other than rheumatoid arthritis were excluded from the study.

\subsection{Clinical and Laboratory Evaluation}

Disease activity was measured by DAS28 and the SDAI $[10,11]$. The patients were clinically examined and the number of swelling joints count (SJC) $(0-28)$ and tender joints count (TJC) (0-28) were noted. The 28 joints included bilateral knees, shoulders, elbows, wrists, metacarpophalangeal and proximal interphalangeal joints. The patients were asked to mark on the visual analogue scale (VAS) of $0-10 \mathrm{~cm}$ according to their global assessment of pain. The physician marked on the VAS of 0-10 $\mathrm{cm}$ according to the physician global assessment (EGA) of the disease activity. Erythrocytes sedimentation rate was measured by Westergren method [15], whereas CRP is measured semi-quantitatively using serial dilutions of serum; each dilution was mixed with a latex reagent and observed for the presence of agglutination [16]. DAS28 was calculated using an internet calculator: http://www.das-score.nl/das28/DAScalculators/dasculators.html.

DAS28 values $>2.6$ and $\leq 3.2$ was considered as low RA disease activity, values $>3.2$ and $\leq 5.1$ was considered as moderate disease activity and those $>5.1$ was considered as high disease activity [17]. Whereas SDAI was calculated by direct summation of the 5 variables SJC, TJC, VAS, EGA, and CRP [11]. SDAI values $>3.3$ and $\leq$ 11 was considered as low RA disease activity, values $>11$ and $\leq 26$ was considered as moderate disease activity and those $>26$ was considered as high disease activity [17].

Functional status of the patients was measured using Stanford Health assessment questionnaire disability index [13]. Calculation of HAQ-DI involves answering of a questionnaire by the patient. It includes questions regarding his/her functional activities under eight domains: dressing, rising, eating, walking, hygiene, grip, reach and usual activities.

Each question is answered on a four level scale of impairment ranging from 0 to 3 : $0=$ no difficulty; $1=$ some difficulty; 2 = much difficulty; and 3 = inability to do.

Additionally morning stiffness of each patient was calculated according to patient approximate. Furthermore, rheumatoid factor was measured qualitatively by latex agglutination test [18].

\subsection{Statistical Analysis}

All data were statistically analyzed using Statistical Package for Social Sciences software version 18 (SPSS v.18); Chi square test for independence was used to test the association between discrete variables; $t$-test was used for two independent samples. Pearson correlation coefficient was used to assess the correlation between continuous variables. All p values used were asymptotic and two sided. Values with $\mathrm{p}<0.05$ were considered significant.

\section{Results}

Table 1 showed the general demographic data of participated patients. It also showed that most patients who included in this study were suffering from moderate - severe RA. The most commonly used DMARD was MTX.

Table 1. Demographic data of patients

\begin{tabular}{|c|c|}
\hline Parameter & Values \\
\hline Age (years) & $45.17 \pm 11.84$ \\
\hline F/M ratio & $74 / 21$ \\
\hline Duration of RA ( years) & $7.53+/-7.22$ \\
\hline Disease activity according to DAS28 & $1(1 \%)$ \\
Low Number (\%) & $28(29.5 \%)$ \\
Moderate Number (\%) & $66(69.5 \%)$ \\
High Number (\%) & \\
Drug used & $80(84 \%)$ \\
MTX Number (\%) & $9(9.4 \%)$ \\
HCQ Number (\%) & $4(4.2 \%)$ \\
MTX+ HCQ Number (\%) & $2(2.1 \%)$ \\
MTX+SZP Number (\%)
\end{tabular}

RA=Rheumatoid arthritis; DAS28=Disease activity score of 28 Joints; MTX= Methotrexate; HCQ=Hydrocychloroquine; SZP=Sulfasalazine

Table 2 showed a significant correlation of HAQDI score with clinical parameters like SJC, TJC, VAS, EGA and morning stiffness. Additionally HAQDI was significantly correlated with disease activity scores DAS28 and SDAI. Furthermore it correlates with inflammatory markers ESR and CRP.

Table 2. Correlation of HAQDI score with RA disease activity, and other inflammatory and clinical parameters

\begin{tabular}{|c|c|c|}
\hline \multirow{2}{*}{ Parameter } & \multicolumn{2}{|c|}{ All participated patients } \\
\cline { 2 - 3 } & $\mathrm{R}$ & P value \\
\hline SJC & 0.372 & 0.000 \\
\hline TJC & 0.510 & 0.000 \\
\hline VAS & 0.683 & 0.000 \\
\hline EGA & 0.650 & 0.000 \\
\hline SDAI & 0.636 & 0.000 \\
\hline DAS28 & 0.655 & 0.000 \\
\hline ESR & 0.285 & 0.005 \\
\hline CRP & 0.225 & 0.029 \\
\hline RF & 0.058 & 0.575 \\
\hline Morning stiffness & 0.446 & 0.000 \\
\hline RA duration & 0.007 & 0.949 \\
\hline Patient's age & -0.019 & 0.855 \\
\hline
\end{tabular}

$\mathrm{SJC}=$ Swollen joint count; TJC=Tender joint count; VAS=Visual analogue scale; EGA=Evaluator global assessment; SDAI=Simplified disease activity index; DAS28=Disease activity score of 28 joints; $\mathrm{ESR}=$ Erythrocyte sedimentation rate; $\mathrm{CRP}=\mathrm{C}$ - reactive protein; $\mathrm{RF}=$ Rheumatoid factor.

Table 3 showed that there was an agreement among DAS28, SDAI and HAQDI for classification of patients to have either high disease or moderate disease activity; 
This agreement result from the significant difference in the values of DAS28, SDAI and HAQDI between patients with moderate disease activity and those with high disease activity.

Table 3. Variation in disability, disease activity, age and duration of RA for patients according to disease activity as measured by DAS28

\begin{tabular}{|c|c|c|c|}
\hline Parameter & $\begin{array}{c}\text { High disease } \\
\text { activity } \\
\mathrm{N}=66\end{array}$ & $\begin{array}{c}\text { Moderate } \\
\text { disease activity } \\
\mathrm{N}=28\end{array}$ & P value \\
\hline DAS28 & $6.43 \pm 0.84$ & $4.46 \pm 0.51$ & 0.000 \\
\hline SDAI & $38.04 \pm 11.67$ & $16.77 \pm 5.71$ & 0.000 \\
\hline HAQDI & $1.9 \pm 0.60$ & $1.16 \pm 0.58$ & 0.000 \\
\hline Duration of RA & $6.89+/-6.69$ & $8.97+/-8.23$ & 0.161 \\
\hline Age of patient & $44.86 \pm 11.28$ & $46 \pm 13.43$ & 0.674 \\
\hline
\end{tabular}

SDAI=Simplified disease activity index; DAS28=Disease activity score of 28 joints; HAQDI=Health assessment questionnaire disability index.

Table 4 showed that HAQDI score was better correlated with clinical parameters in patients with high disease activity than those with moderate activity; Moreover HAQDI score was well correlated with disease activity as measured by SDAI in patients with moderate and those with high disease activity.

Table 4. Correlation of HAQDI score with inflammatory markers, clinical parameters and disease activity according to patients' disease activity

\begin{tabular}{|c|c|c|c|c|}
\hline \multirow{2}{*}{ Parameter } & \multicolumn{2}{|c|}{$\begin{array}{c}\text { High disease activity } \\
\mathrm{N}=66 \\
\end{array}$} & \multicolumn{2}{|c|}{$\begin{array}{l}\text { Moderate disease activity } \\
\mathrm{N}=28 \\
\end{array}$} \\
\hline & $\mathrm{R}$ & $P$ value & $\mathrm{R}$ & $P$ value \\
\hline SJC & 0.166 & 0.182 & 0.189 & 0.336 \\
\hline TJC & 0.342 & 0.005 & 0.310 & 0.109 \\
\hline VAS & 0.569 & 0.000 & 0.517 & 0.009 \\
\hline EGA & 0.481 & 0.000 & 0.536 & 0.003 \\
\hline SDAI & 0.484 & 0.000 & 0.458 & 0.014 \\
\hline DAS28 & 0.560 & 0.000 & 0.263 & 0.177 \\
\hline ESR & 0.196 & 0.115 & -0.324 & 0.093 \\
\hline CRP & 0.174 & 0.163 & -0.321 & 0.096 \\
\hline $\mathrm{RF}$ & 0.001 & 0.993 & -0.031 & 0.875 \\
\hline stiffness & 0.303 & 0.013 & 0.515 & 0.005 \\
\hline RA duration & 0.006 & 0.992 & 0.246 & 0.208 \\
\hline Patient's age & 0.208 & 0.094 & -0.428 & 0.023 \\
\hline
\end{tabular}

$\mathrm{SJC}=$ Swollen joint count; TJC=Tender joint count; VAS=Visual analogue scale; EGA=Evaluator global assessment; SDAI=Simplified disease activity index; DAS28=Disease activity score of 28 joints; $\mathrm{ESR}=$ Erythrocyte sedimentation rate; $\mathrm{CRP}=\mathrm{C}$ - reactive protein; $\mathrm{RF}=$ Rheumatoid factor.

\section{Discussion}

This study (as shown in Table 2) showed that HAQDI score was well correlated with clinical parameters like TJC, VAS, EGA, SJC and morning stiffness, similarly Ghosh et al showed that TJC, VAS and EGA are well correlated with HAQDI score [14]; whereas Erdem et al showed that HAQDI score is strongly correlated with morning stiffness in patients with RA [19]; while SJC was shown to be correlated with HAQDI score in patients with gout [20]. Moreover inflammatory markers, ESR and CRP was also correlated with HAQDI score but to a lesser degree than other clinical parameters, similarly Ghosh et al showed that HAQDI is less correlated with ESR than other clinical parameters [14]; Furthermore, this study showed that HAQDI score was significantly and strongly correlated with disease activity scores (SDAI and DAS28), which is similar to the finding of other studies, that showed that a good correlation of HAQDI score with DAS28 and SDAI [11,21].
Some studies consider the importance of HAQ DI score in assessing RA disease activity is relative because of the difference in HAQDI values between patients and physicians [22]. However the current study is different from that study since HAQDI score was correlated with all clinical parameters that obtained from the patients and those that are obtained by clinical examination or even by laboratory analysis.

It is well known that lack of accessibility to rheumatologists and discomfort in prescribing DMARDs for patients with RA are potential barriers to optimal treatment [23]. This will highlight the importance of the current study findings especially the correlation of HAQDI with disease activity scores since measuring RA disease activity by either DAS28 or SDAI require an accurate evaluation of the patient clinical status by a physician, which means that the patient must go to meet the physician in the hospital or in the out patient clinic if the patient can afford that in order to be examined by the physician; however and whatever the site at which the patient disease activity can be assessed, it will not be an easy task for a patient with rheumatoid arthritis to dress, and walk to reach his/her physician, besides that the situation of traffic accidents and road closure in Iraq, is and additional cause that makes the arrival of patient to the physician more hard. Moreover the calculation of both DAS28 and SDAI require not only clinical parameters but also laboratory parameters, this in turn means that the patient is in need for invasive procedures which may be painful and costly to the patient, especially for patients with poor socio economic status in $3^{\text {rd }}$ world like Iraq, that may result in decreasing patient compliance for regular follow up. Hence, even if the patients fail their appointment for any reason as mentioned above, it will allow the physicians to assess the disease activity and the response to treatment to a larger extent depending on the result of HAQDI score through a mobile or even through a message by an email. Since some other studies states that HAQDI score worse as the duration of RA become longer [24], while other studies states that old age of RA patient may be associated with disability and higher HAQDI scores [25]; A correlation analysis of HAQDI with patient age and RA disease duration was done to exclude any doubts about the current study findings, and it was found that there is no any correlation between these parameters and HAQDI score which further confirm the results of this study.

The finding of HAQDI correlation with disease activity score in this study was further confirmed by the presence of statistically significant difference (Table 3) in the values of HAQDI between RA patients with moderate disease activity and those with high disease activity as measured by DAS28 and SDAI; Meanwhile there was no any difference between the age of patients or the duration of RA among patients with moderately and highly active RA. Additionally the results of this study showed that HAQDI correlation with RA disease activity, clinical parameters and even with inflammatory markers is better for RA patients with high disease activity than those with moderate disease activity, this observation may not lessen the importance of this study findings, since patients with more severe symptoms and high disease activity require more frequent follow up than those with lower disease activity [4], and those patients with high disease activity 
are the ones who can't meet their doctors easily because of limitation in their activities by the active disease.

In conclusion HAQDI score is a valid and useful tool to monitor disease activity and response to treatment in Iraqi patients with highly active RA.

\section{References}

[1] Cojocaru M, Cojocaru IM, Silosi I, Vrabie CD, Tanasescu R. Extra-articular manifestations in rheumatoid arthritis. Maedica (Buchar) 2010; 5:286-91.

[2] Schneeberger EE, Citera G, Maldonado Cocco JA, Salcedo M, Chiardola F, Rosemffet MG, Marengo MF,Papasidero S, Chaparro Del Moral R, Rillo OL, Bellomio V, Lucero E, Spindler A, Berman A, Duartes Noe D, Barreira JC, Lázaro MA, Paira SO. Factors associated with disability in patients with rheumatoid arthritis. J Clin Rheumatol. 2010 Aug;16(5):215-8.

[3] Prete M, Racanelli V, Digiglio L, Vacca A, Dammacco F, Perosa F. Extra-articular manifestations of rheumatoid arthritis: An update. Autoimmun Rev. 2011 Dec; 11(2):123-31. doi: 10.1016/j.autrev.2011.09.001. Epub 2011 Sep 10.

[4] Smolen JS, Aletaha D, Bijlsma JW, Breedveld FC, Boumpas D, Burmester G, Combe B, Cutolo M, de Wit M, Dougados M, Emery P, Gibofsky A, Gomez-Reino JJ, Haraoui B, Kalden J, Keystone EC, Kvien TK,McInnes I, Martin-Mola E, Montecucco C, Schoels M, van der Heijde D; T2T Expert Committee. Treating rheumatoid arthritis to target: recommendations of an international task force. Ann Rheum Dis. 2010 Apr;69(4):631-7. doi: 10.1136/ard.2009.123919. Epub 2010 Mar 9.

[5] Roy Fleischmann. Don't forget traditional DMARDs. Rheumatology 2011;50:429-430.

[6] Mary Anne Koda-Kimble, Young L Y, Kradjan WA and Guglielmo BJ. Applied therapeutics: the clinical use of drugs. 9th edn; Philadelphia: Wolters KluwerHealth/Lippincott Williams \& Wilkins 2009; CH 43:1-44.

[7] Young A, Dixey J, Cox N, Davies P, Devlin J, Emery P, Gallivan S, Gough A, James D, Prouse P, Williams P, Winfield J. How does functional disability in early rheumatoid arthritis (RA) affect patients and their lives? Results of 5 years of follow-up in 732 patients from the Early RA Study (ERAS). Rheumatology (Oxford). 2000 Jun;39(6):603-11.

[8] Farheen K, Agarwal SK. Assessment of disease activity and treatment outcomes in rheumatoid arthritis. J Manag Care Pharm. 2011 Nov-Dec;17(9 Suppl B):S09-13.

[9] Mitchell K. shared care - the way forward for patient oriented follow up care in rheumatoid arthritis. Rheumatology 2000;39:457-58.

[10] Prevoo ML, van’t Hof MA, Kuper HH, van Leeuwen MA, van de Putte LB, van Riel PL. Modified disease activity scores that include twenty-eight-joint counts. Development and validation in a prospective longitudinal study of patients with rheumatoid arthritis. Arthritis Rheum 1995; 38: 44-8.

[11] Smolen JS, Breedveld FC, Schiff MH, Kalden JR, Emery P, Eberl G, van Riel PL, Tugwell P. A simplified disease activity index for rheumatoid arthritis for use in clinical practice. Rheumatology 2003; 42:244-57.

[12] Alchy EM, Gorial FI, Majeed IA, Hussain SA. Validity of simplified disease activity index using CRP titer in comparison to disease activity score-28 joints in Iraqi patients with active Rheumatoid arthritis. J Exp Integr Med. 2012; 2(3): 231-236.

[13] Bruce B, Fries JF. The Stanford health assessment questionnaire: a review of its history, issues, progress, and documentation. J Rheumatol 2003; 30:167-78.

[14] Ghosh A, Ghosh B, Pain S, Pande A, Saha S, Banerjee A, Biswas AB. Comparison between DAS28, CDAI and HAQ-DI as tools to monitor early rheumatoid arthritis patients in eastern India. Indian Journal of Rheumatology 2011; 30(6): 116-122.

[15] National Committee for Clinical Laboratory Standards (NCCLS). Reference and Selected Procedure for the Erythrocyte Sedimentation Rate (ESR) Test; Approved Standard - Fourth Edition. NCCLS document H2-A4, Wayne, PA, USA 2000.

[16] Philip AG, Andrews PA. Rapid determination of C-reactive protein levels: semi-quantitative versus quantitative. Clin Lab Observ 1986; 110:263-5.

[17] Aletaha D, Smolen J. The Simplified Disease Activity Index (SDAI) and the Clinical Disease Activity Index (CDAI): a review of their usefulness and validity in rheumatoid arthritis. Clin Exp Rheumatol. 2005 Sep-Oct;23(5 Suppl 39):S100-8.

[18] Singer, J.M. C.M., Plotz, E. Parker \& S.K. Elster. Amer. J. Clin. Path 1957;28: 611.

[19] Altınkesen E, Gelecek N. Functional status and quality of life in patients with early and late stage rheumatoid arthritis. Fizyoter Rehabil. 2011;22(2):93-99.

[20] Alvarez-Hernández E, Peláez-Ballestas I, Vázquez-Mellado J, Terán-Estrada L, Bernard-Medina AG,Espinoza J, Aceves-Avila FJ, Goycochea-Robles MV, Garza M, Ventura L, Burgos-Vargas R;REUMAIMPACT. Validation of the Health Assessment Questionnaire disability index in patients with gout. Arthritis Rheum. 2008 May 15;59(5):665-9. doi: 10.1002/art.23575.

[21] Drossaers-Bakker KW, De Buck M, Van Zeben D, Zwinderman AH, Breedveld FC, Hazes JMW. Long-term course and outcome of functional capacity in rheumatoid arthritis: the effect of disease activity and radiologic damage over time. Arthritis Rheumat 1999; 42: 1854-60.

[22] Bensen, William, Choquette, Denis, Baker, Milton F., Otawa, Susan M., Khalil, Hayssam; Identification of Four Parameters That Drive the Discordance Between the Patient and Physician Global Assessment in Rheumatoid Arthritis [abstract]. Arthritis Rheum 2012;64 Suppl $10: 2108$.

[23] Garneau KL, Iversen MD, Tsao H, Solomon DH. Primary care physicians' perspectives towards managing rheumatoid arthritis: room for improvement. Arthritis Res Ther. 2011;13(6):R189. doi: 10.1186/ar3517. Epub 2011 Nov 18.

[24] Scott DL, Pugner K, Kaarela K, Doyle DV, Woolf A, Holmes J, Hieke K. The links between joint damage and disability in rheumatoid arthritis. Rheumatology (Oxford). 2000 Feb;39(2):122-32.

[25] Cho SK, Sung YK, Choi CB, Cha HS, etal. Do patients with elderly - onset rheumatoid arthritis have severe functional disability?. Semin Arthritis Rheum. 2012 Aug;42(1):23-31. doi: 10.1016/j.semarthrit.2012.02.004. Epub 2012 Mar 31. 